\title{
Preliminary experimental data to the hepatic effect of khat (Catha edulis)
}

\author{
Erica E Balint ${ }^{1}$, H Ghebrekidan $^{2}$ and GA Balint ${ }^{3 *}$ \\ ${ }^{1}$ University of Szeged, Albert Szent - Gyorgyi Medical School, Dept. of Human Anatomy, Szeged, Hungary \\ ${ }^{2}$ University of Asmara, Faculty of Medicine, Asmara, Eritrea \\ ${ }^{3}$ University of Szeged, Albert Szent-Gyorgyi Medical School, Laboratory of Clinical Pharmacology, Dept. of Psychiatry, Szeged, Hungary
}

The chewing of khat (Catha edulis) leafs has been used traditionally as a socializing session - and this is still very much the case, - mainly in the eastern part of Africa as well, as in the Arabian Peninsula. The chewing of fresh khat leaves has a stimulating effect and causes a certain degree of euphoria. According to WHO's estimation 5 - 10 million people use to use it every day [1].

Moreover, during the last decade(s) khat production became a lucrative business as well. In Somalia, - for example, - the demand for khat was so heavy that 20 tons, - worth USD 800.000, - were shipped daily from Kenya before the ban by the Supreme Islamic Courts Council [2].

During the last years the demand has returned nearly to the previous level, but the problem is growing again because the wellknown military interventions.

Khat is now available almost everywhere, - all over the world - as the result of migration due to different causes, an increase is in its use and the associated socioeconomic and health problems among its users. Khat already has a global market and a recognized economic value.

In the USA khat is being sold for 300 - 400 USD a kilo, - with a bundle of leaves selling for 15 - 30 USD.

Many different compounds are found in the khat leaves, - including alkaloids, terpenoids, flavonoids, sterols, glucosides, tannins, amino acids, minerals and others [1].

The phenylalkylamines and cathedulins are the major alkaloids in it.

The khat phenylalkylamines comprise cathinone (CTN) and the two diastereoisomers cathine (CAT).

These compounds are structurally related to amphetamine and noradrenaline (norepinephrine).

As CTN is presumably the main psychoactive component of khat, it is therefore mainly responsible for the wanted stimulating and euphoric effect.

According to our own investigations (unpublished data,1990;) $100 \mathrm{~g}$ fresh khat leaves in Addis Ababa region, (Ethiopia;) contain approximately $40 \mathrm{mg}$ CTN, $120 \mathrm{mg}$ CAT, $5 \mathrm{mg}$ norpseudoephedrine (plus more than 30 minor compounds).

During an average khat-session the users use to chew 200 - $400 \mathrm{~g}$ of leaves. Therefore, the CTN dose is approximately $80-160 \mathrm{mg}$ (which corresponds a- bout a $1-2 \mathrm{mg} / \mathrm{kg}$ of body weight dose;) - during a $4-6$ hour long togetherness.
Considering that CTN's metabolism is rapid we have concluded that in our preliminary experimental investigations a 500 and a $1000 \mu \mathrm{g} /$ kg single ("rap-id") dose of CTN will be appropriate and informative.

Chapman and his co-workers reported [3] their observation on six patients whose use of khat was associated with severe acute hepatitis. The patients were not related with each other, neither geographically nor temporally.

All of their patients had previous hepatic problems, mainly hepatitis, - and according to the mentioned authors no other cause for their liver disease was found than khat consumption. Moreover, a high concentration of CTN was found in the liver tissue from one patient.

Khat related hepatotoxicity has been already demonstrated, which is similar those of other amphetamine-like compounds' hepatic effect [4].

Considering the above-mentioned facts and results we have decided to investigate the possible earliest effect of CTN on the ultrastructure of rat liver.

During these investigations 45 adult Wistar rats of both sexes were used. They body weight was $200-230 \mathrm{~g}$ and they were treated as follows:

The animals in the control group $(\mathrm{n}=15)$ received $0.5 \mathrm{ml}$ sterile, pyrogen-free normal saline solution intraperitoneally (i.p.)

The treated animals received i.p. $500(\mathrm{n}=15)$ and $1000(\mathrm{n}=15) \mu \mathrm{g} /$ $\mathrm{kg}$ CTN respectively, in sterile, pyrogen-free normal saline solution.

After $24 \mathrm{~h}$ waiting period all of the animals were killed by decapitation. Within 60 seconds after decapitation samples were taken approximately from the same part of the liver, - right lateral lobe, - for electron microscopic investigation.

The liver slices were fixed in 2.5 per cent glutaraldehyde solution at $0-4^{\circ} \mathrm{C}$. After the fixation they were dehydrated in alcoholic-series, then were embedded in araldite. In the blocks, - during dehydration, - they were contrasted by uranyl-acetate, - dissolved in 70 per cent ethanol, - and on the sections by lead citrate. The photomicrographs were taken by a Zeiss-EM-9S-2 type electron microscope.

Correspondence to: GA Balint, University of Szeged, Albert Szent-Gyorgyi Medical School, Laboratory of Clinical Pharmacology, Department of Psychiatry, Szeged, Hungary, E mail: profbalint@yahoo.com

Received: November 12, 2017; Accepted: December 05, 2017; Published: December 08, 2017 
It seems that basically no structural changes can be seen in the treated animals. The basic structure of the liver is normal compared to the control. The only visible change is that the surface area of the mitochondria in the untreated liver was $59.67 \mathrm{~mm} 2$ (counted always minimally 100 mitochondria;) if the magnification was $x 11.700$, while in the case of $500 \mu \mathrm{g} / \mathrm{kg}$ CTN dose the mitochondrial surface area was $94.66 \mathrm{~mm} 2$ and in the case of $1000 \mu \mathrm{g} / \mathrm{kg}$ CTN treatment the surface of the mitochondria grew to $130.54 \mathrm{~mm} 2$ (among the same experimental circumstances;) which latter is a significant ( $<<0.02$ Student's $t$-test; enlargement compared to control.

Considering Chapman et al. [3] result, we conclude that this, mitochondrial effect might be the first (pathological) sign of the khatrelated hepatic toxicity which later, after a long and repeated effect of CTN (khat chewing habit is a longlasting behaviour;) finally may (will?) cause hepatitis.

Further investigations seem to be needed along this line, what we want to complete.

\section{References}

1. Balint EE, Falkay G, Balint GA (2009) Khat - a controversial plant. Wien Klin Wochenschr 121: 604-614. [Crossref]

2. Wax E (2006) Khat trade rules Somalia. Washington Post Foreign Service.

3. Chapman MH, Kajihara M, Borges G, O’Beirne J, Patch D, et al. (2010) Severe, acute liver injury and khat leaves. $N$ Engl J Med 362: 1642-1644. [Crossref]

4. Kalix P (1988) A plant with amphetamine effects. $J$ Subst Abuse Treat 5: 163-169. [Crossref]

Copyright: (C2017 Balint EE. This is an open-access article distributed under the terms of the Creative Commons Attribution License, which permits unrestricted use, distribution, and reproduction in any medium, provided the original author and source are credited. 